\title{
Characterisation of phase transformations and stresses during the welding of a ferritic mild steel
}

\author{
D. Dye ${ }^{\mathrm{a}}$, H.J. Stone ${ }^{\mathrm{b}}$, M. Watson ${ }^{\mathrm{c}}$ and R.B. Rogge ${ }^{\mathrm{c}}$

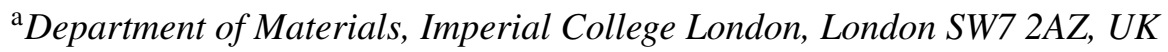 \\ ${ }^{\mathrm{b}}$ Department of Materials Science and Metallurgy, University of Cambridge, 27 Charles \\ Babbage Road, Cambridge CB3 OFS, UK \\ ${ }^{\mathrm{c}}$ National Research Council, Chalk River Laboratories, Chalk River, Ontario, KOJ 1J0, \\ Canada
}

\begin{abstract}
The transient stresses and phase evolution have been characterised in the quasi-steady state produced around a gas tungsten arc welding (GTAW) torch in a plain carbon (ASTM 1018) steel using in situ neutron diffraction. A novel method has been developed to isolate the deviatoric or plane stress state in the presence of isotropic contributions to the lattice parameter, such as thermal expansion and solute content. The stress state was found to evolve in the anticipated manner, with compressive stresses ahead of the weld and tensile stresses behind the weld, in the weld and heat affected zone, and compression in the far field behind the weld. In particular, the region of compression in the heat-affected zone adjacent to and just behind the welding torch expected from weld models was observed. The evolution of phase fraction around the weld was also determined using the technique and the stresses obtained from the ferrite phase.
\end{abstract}

\section{Introduction}

Over the past 25 years, much progress has been made in the development of models for the prediction of the temperature and stress fields produced during fusion welding, with particular emphasis on the prediction of residual stresses [3, 13, 14]. The residual stress state produced in and around the weld depends on the alloy and phase transformations that occur, the size and shape of the weld pool and on the welding speed. Unfortunately, it is difficult to predict, a priori, the weld pool shape due to the large number of variables involved. The situation is complicated by a lack of knowledge of the fundamental physical constants relating to the arc and molten pool, and the way in which the arc couples with the material, for example, the arc pressure and electromagnetic stirring of the pool by the arc. In spite of 
these difficulties, some models capable of predicting weld pool shapes have been successfully created $[15,17]$.

To ascertain both the residual stress state and microstructure around the weld, a modelling-based approach is attractive, since complete experimental characterization is typically both time consuming and expensive. However, such models demand knowledge of the temperature dependence of the thermophysical and mechanical properties of the material along with the distribution and magnitude of heat input into the material. Obtaining these data is again usually time-consuming and expensive, but has been performed in very many successful weld models in a range of materials, for example in the welding of steels [5, 20], aluminium [19] and nickel $[7,21]$ alloys.

Such weld models are often verified by reference to measured residual stress distributions and to the final distortion found in the workpiece, and are calibrated using the temperature evolution in the heat affected zone measured using thermocouples. Among residual stress measurement techniques, neutron or synchrotron diffraction are often preferred, since these techniques are non-destructive, capable of characterizing the spatial distribution of the stress field rather than performing measurements at individual points, and can measure stresses at depth. The ability to perform measurements at depth is particularly advantageous compared to the leading alternatives of incremental hole drilling and laboratory X-ray diffraction using the $\sin ^{2} \psi$ technique [22] as asymmetry in the stress state through the thickness of the component may be significant. A further strength of these diffraction based methods is that the measurement of strain is direct, using the expansion in the interatomic spacing, rather than using strain relaxation during material removal, to infer the stress state.

However, verification of a weld thermo-mechanical model using the residual stress field and distortion may not uniquely determine the transient evolution of deformation during welding. In the very latest thermo-mechanical models, e.g. for weldability and cracking [6]; for those used to rationalise the evolution of stress during thermal tensioning techniques such as low stress low distortion welding [8] or where phase transformations are used for stress relief [4], the transient stress state is critical to the scientific question being posed. Therefore it is of great interest to be able to measure the evolution of stress during welding.

In this paper we present, for the first time, measurements of the two-dimensional stress field established in the quasi-steady state that exists around a moving weld pool using neutron diffraction.

Measurements of phase fraction evolution have been presented before, most notably in 1045 steel $[9,10]$, a 2205 duplex stainless steel [12] and Ti-6Al-4V [11] by Elmer et al.; in an Fe-C-Al-Mn steel by Babu et al. [1]; and in 1005 steel by Zhang et al. [25]. In all of these studies, the spatial distribution of phases pro- 
duced around a welding torch were determined using time-resolved X-ray diffraction at a synchrotron source. However, measurement of stress is significantly more complicated, because changes in lattice parameter are not solely due to mechanical strains but also due to thermal expansion of the material and compositional variations associated with phase transformations. In spite of these difficulties, two attempts to measure stresses in situ along a one dimensional line have recently been reported in a friction stir weld on an aluminium alloy, which does not exhibit any phase transformations [23, 24]. The magnitude of the mechanical, thermal and compositional contributions to the lattice parameter are similar; using the expressions of Onink and Root [18], a $50^{\circ} \mathrm{C}$ temperature variation, which is at the limit of positioning accuracy for placing a neutron diffraction gauge volume near a thermocouple, corresponds to a change in lattice parameter of ferrite of $2.88 \times 17.5 \times 50 \times 10^{-6}=2.52 \times 10^{-3} \AA$. In comparison, a 0.1 at.\% variation in carbon content of austenite corresponds to a change of $0.75 \times 10^{-3} \AA$. The solubility of carbon in ferrite is small, so solute is only a significant concern in the austenite phase. In contrast, a hydrostatic stress of $100 \mathrm{MPa}$ in ferrite would produce a change in lattice parameter of $2.88 \times(100 / 180) \times 10^{-3} \sim 1.6 \times 10^{-3} \AA$, assuming a bulk modulus of $180 \mathrm{GPa}$. The similarity between the magnitudes of these effects on the lattice parameter is such that they cannot be neglected. The successful determination of the transient stresses produced during welding therefore demands a method to deconvolute the mechanical contribution to the measured lattice parameters from these other effects.

\section{Methodology}

Conventionally the determination of stresses by diffraction-based methods is achieved by measurement of the lattice parameter, $a_{i}$, in a given direction, $i$, in the sample. This is then converted to a strain, $\varepsilon_{i}$, by the use of a stress-free lattice parameter, $a_{0}$, using

$$
\varepsilon_{i}=\Delta a / a_{0}=a_{i} / a_{0}-1
$$

in which $\Delta a=a_{i}-a_{0}$.

By performing strain measurements in different directions the full strain tensor may be determined, from which the associated stress tensor may be calculated using the appropriate elastic constants. Typically, it is assumed that the three principal directions are known a priori, defined by the symmetry of the component. In the analysis of residual stresses in welds it is common to take these to be the welding direction, the through thickness direction and a third perpendicular direction transverse to the weld. By making this assumption, the minimum number of independent strain measurements required to determine the stress tensor is reduced from six to three. 
However, this approach is not feasible for the measurement of strains around a weld as the strain-free lattice parameter cannot be found because of temperature and composition variations due to the phase transformations and the thermal profile around the weld. As a result, at each measurement point insufficient data can be acquired to uniquely determine the isotropic lattice parameter and three normal strains. This problem can be solved in two ways, either (i) by determining the deviatoric stress state only or (ii) assuming a state of plane stress. Both of these approaches are described below.

Deviatoric stresses only: If the lattice parameter is measured in three principal directions, $i$, the isotropic, hydrostatic lattice parameter, $a_{h}$, may be defined by $a_{h}=\frac{1}{3} \Sigma a_{i}$. The deviatoric strain, $\varepsilon_{i}^{\prime}$, can then be obtained using

$$
\varepsilon_{i}^{\prime}=\frac{\Delta a}{a_{h}}=\frac{a_{i}}{a_{h}\left(C, T, \varepsilon_{h}\right)}-1
$$

where $a_{h}$ is a function of composition, $C$, thermal strain due to temperature, $T$, and hydrostatic strain, $\varepsilon_{h}=\frac{1}{3} \Sigma \varepsilon_{i}$. For an isotropic material, the normal stresses, $\sigma_{i}$, can be found from the normal strains, $\varepsilon_{i}$, using

$$
\sigma_{i}=2 G \varepsilon_{i}+3 \lambda \varepsilon_{h}
$$

Where $\lambda$ is Lamé's constant, given by $\lambda=v E /(1+v)(1-2 v)$, in which $E$ is the Young's modulus and $v$ is the Poisson's ratio, and the shear modulus, $G$, is given by $2 G=E /(1+v)$. The deviatoric stresses, $\sigma_{i}^{\prime}$, can therefore simply be obtained from

$$
\sigma_{i}^{\prime}=2 G \varepsilon_{i}^{\prime}
$$

\section{Plane stress assumed:}

For an orbital weld on a tube within the cylindrical polar reference frame where the principal axes are assumed to lie along the radial $(r)$, hoop $(\theta)$ and axial $(z)$ directions, if a state of plane stress is assumed with $\sigma_{r}=0$, then using the three permuations of Hooke's Law it can be shown that

$$
\varepsilon_{r}=\frac{-v}{1-v}\left(\varepsilon_{\theta}+\varepsilon_{z}\right)
$$

Substitution for the strains in this expression with Equation 1 yields

$$
a_{0}(C, T)=\frac{(1-2 v) a_{r}+v\left(a_{r}+a_{\theta}+a_{z}\right)}{1+v}
$$

at which point all three principal strains and in-plane stresses, $\sigma_{\theta}$ and $\sigma_{z}$, can be found trivially from Equations 1 and 5 .

In the present paper, the plane stress assumption has been employed as the samples 
were thin (3.2 mm thickness). From the measured time-of-flight neutron diffraction data an overall lattice parameter, $a$, was determined by Rietveld refinement of the entire diffraction spectrum. Previous work has shown that such a fitting procedure is robust and that bulk elastic constants can safely be used, even in the presence of moderate textures and elastic anisotropy [2]. The final problem is to determine a set of appropriate elastic constants for the material being used. Rigorous conversion of the measured deviatoric strains to stresses would require use of the temperature dependent elastic constants. However, if such data are to be used, the temperature profile around the weld pool must be determined, either using a model, thermocouples or an optical pyrometer. Alternatively, the hydrostatic strain might be assumed to be entirely a consequence of thermal expansion and therefore used to determine the temperature. However, for the sake of simplicity in this first study of stress fields around welds, constant values of the elastic moduli of bcc ferrite $(E=205 \mathrm{GPa}$, $v=0.29)$ were used. It is acknowledged that the moduli of bcc ferrite have a temperature dependence, which will reduce the magnitude of the stresses determined at high temperature.

\section{Experimental Description}

Measurements of the phase distributions and strains in the vicinity of the welding torch during gas tungsten arc (GTA) welding of ASTM 1018 steel tubes were performed using the ENGIN-X time-of-flight neutron diffractometer at ISIS, Didcot, UK. ASTM 1018 steel is a ferritic low carbon steel with a nominal C content of $0.15-0.20$ and $\mathrm{Mn}$ content of $0.60-0.90$, in wt.\%, with the balance Fe. The tubes were $203.3 \mathrm{~mm}$ in diameter and $3.2 \mathrm{~mm}$ in thickness and were fabricated by electrical welding of steel sheet. Any preexisting residual stresses would be expected to be uniform around the tubes and, as such, by taking the lattice parameter of the unwelded tube as the reference lattice parameter for strain calculation, any strains measured may be directly associated with the thermal expansion and stress response of the steel during the welding process.

Gas tungsten arc welding was performed to manufacture autogenous, bead-on-plate welds. DCEN conditions were employed using a 35A input current, a nominal torch-tip potential of $14 \mathrm{~V}$ and a welding speed of $0.5 \mathrm{~mm} \mathrm{~s}^{-1}$. The nominal heat input was therefore $1000 \mathrm{~W} \mathrm{~mm}^{-1}$. To maximise arc stability and the welding thermal efficiency, an Ar-25\%He welding gas mixture was used. In order to remove the residual heat during welding, He gas cooled in liquid nitrogen was passed over the opposite side of the tube. The torch-tip distance was maintained at $3 \mathrm{~mm}$ using a sprung slide arrangement and a grub screw in contact with the tube.

[Fig. 1 about here.]

Orbital welds were made around the tube, with the tube rotating in place under a 
static welding torch. This enabled measurements to be made in the quasi-steady state that exists in the vicinity of the welding torch. The torch location was measured using the neutron beam prior to welding in order to reliably locate the measurement positions. At each measurement position, diffraction spectra were simultaneously acquired from the two detectors on the ENGIN-X instrument using count times of $60 \mathrm{~s}$, with a dead time between acquisitions of $\sim 20 \mathrm{~s}$ to move the torch, tube and rotation stage to another position relative to the torch and for detector data read-out. Each orbital weld was started just ahead of the axial tube seam weld and measurements were avoided from the vicinity of the seam as it was anticipated that both the local microstructure and preexisting residual stress field may differ from the remainder of the tube in this region. In this way, it was possible to collect data from 14 positions from each weld during the $\sim 21$ minutes required for the tube to complete one revolution. During each such weld, data were acquired along a trace parallel to the weld path at $5 \mathrm{~mm}$ intervals from $20 \mathrm{~mm}$ ahead of the weld to $45 \mathrm{~mm}$ behind the weld. Measurements were made on multiple welds using several tubes cut from the same length of pipe at locations 5, 8, 12, 18 and $24 \mathrm{~mm}$ from the weld path. The fusion zone was avoided. As two strain components could be acquired simultaneously, two sets of measurements were made so that each of the three assumed principal strain directions could be obtained; one with the tube vertical, to acquire data from the radial and hoop directions, and another with the tube horizontal to collect data from the axial and hoop directions. Additional measurements were also made in the fusion zone in a single orientation to capture just the phase evolution. The two setups are shown schematically in Figure 1. The incident beam size was defined using slits in the incident beam and collimators on the detectors to obtain a gauge volume of $2 \times 2 \times 2 \mathrm{~mm}$.

In addition, nominally identical measurements were performed at the L3 diffractometer at NRC Chalk River, ON, Canada using monochromated neutrons of wavelength $1.56 \AA$ and the $\{211\}$ ferrite peak, which was found at a diffraction angle of $83.1^{\circ}$. The welding conditions and diffraction geometries closely matched those used at ISIS, Figure 1(d). Measurements of lattice spacing were made in the hoop, radial and axial directions in the tube. Due to the additional uncertainty in position generated by performing three measurements rather than two, it was not possible to reliably analyse these data for stresses, although the hydrostatic lattice parameter variation could be attained.

\section{Results and Discussion}

\section{Microstructure}

A macrograph of the weld cross-section is shown in Figure 2, together with the parent metal and fusion zone microstructures. The base metal was ferritic-pearlitic, 
with grain boundary carbides and a mixture of ferrite and pearlite grains that transformed from the austenite phase. The weld microstructure was composed of grain boundary ferrite with some Widmanstätten ferrite growing from the grain boundaries, and pearlite in the interior of the grains. The parent metal grain size was around $30 \mu \mathrm{m}$ and the fusion zone grains were around $250 \mu \mathrm{m}$ in width and several $\mathrm{mm}$ long in the welding direction.

[Fig. 2 about here.]

[Fig. 3 about here.]

\section{Diffraction data}

Examples of the diffraction patterns collected along the track $5 \mathrm{~mm}$ from the weld path in the vicinity of the weld are shown in Figure 3. Ahead of the weld, only the ferrite phase was detected; the carbides known to be present in the material were not observed due to the short acquisition times and low volume fraction. In the data acquired, the first five bcc peaks were readily discerned and fitted by Rietveld refinement using the GSAS program [16] with peak profiles described by a convolution of pseudo-Voigt and back to back exponential functions. $5 \mathrm{~mm}$ from the weld center line and adjacent to the welding torch, first a mixture of bcc ferrite and fcc austenite was detected and until $10 \mathrm{~mm}$ behind the weld torch a pure austenite structure was measured. As the material in the heat affected zone cooled, the ferrite phase was again detected in the two phase field $20 \mathrm{~mm}$ behind the welding torch until only ferrite was observed again $25 \mathrm{~mm}$ behind the torch. As with the data acquired from the pure ferrite material, five peaks were discerned from the austenite phase and used in fitting the data.

The ferrite phase fractions extracted using Rietveld refinement are shown in Figure 4. Material in the two-phase field was measured at nine locations and $100 \%$ austenite was identified at a further eleven locations. Immediately ahead of the weld torch the heating rate is typically so high that the two phase region would be expected to be less than $1 \mathrm{~mm}$ in length and therefore it was not detected using the gauge volume and relatively course measurement grid employed here.

[Fig. 4 about here.]

The spatial variation of the ferrite $a_{0}$ lattice parameter is shown in Figure 5, plotted as a strain referred to the far field ahead of the weld. If $a_{0}$ were primarily a consequence of thermal expansion, then the measured change of $0.0266 \AA$ between the smallest and largest values of $a_{0}$ recorded would correspond to a temperature change of $0.0266 /\left(2.88 \times 17.5 \times 10^{6}\right) \sim 530^{\circ} \mathrm{C}$. As a result of the considerable statistical deviations seen in the data recorded, a better comparison may be made between the mean of the three largest lattice parameters recorded and the mean of the 
three smallest. This difference, $0.0240 \AA$, suggests a temperature rise of $\sim 480^{\circ} \mathrm{C}$. These values are far smaller than the austenite transformation temperature; the difference may be attributed to the effect of hydrostatic compression that occurs due to constrained thermal expansion in the region of the weld. However, they indicate the desirability of the approach of only attempting to measure the in-plane stress components, ignoring the hydrostatic and thermal strains. They also indicate that the approach of ascribing all of the hydrostatic change in lattice parameter to heating in order to determine temperature and hence the appropriate elastic constants would have been erroneous.

[Fig. 5 about here.]

The measurements made using the $\{211\}$ peak at Chalk River are broadly consistent with those made at using the Rietveld-refined lattice parameter at ISIS, although the ISIS measurements generally show slightly greater variation and the form of the profile around the weld pool observed is slightly different.

[Fig. 6 about here.]

[Fig. 7 about here.]

Stresses

Before reviewing the measured stress data, it is useful to review the expected stress profile around a weld. A generic depiction of this stress variation, derived from a weld model for a single-phase material [6] is shown in Figure 6. As the material is heated up ahead of the welding torch it expands, but this expansion in constrained by the surrounding cool material and so a large region of hydrostatic compression is expected. This results in yielding of the material in the heat affected zone because the yield strain is typically much smaller than the amount of thermal expansion - in a plain carbon steel with a bulk modulus of $180 \mathrm{GPa}$, a yield stress of $350 \mathrm{MPa}$ and a thermal expansion coefficient of $17.5 \times 10^{-6} \mathrm{~K}^{-1}$ this point would be reached at on the order of $(350 / 180) / 0.0175 \sim 110^{\circ} \mathrm{C}$. The compressive plastic strain thereby produced makes the material in the heat affected zone smaller in the longitudinal and transverse directions and therefore when the material cools tensile stresses are produced in the weld and heat affected zone, which are typically of magnitude equal to the yield stress. In the vicinity of the weld itself the compressive stress drops as the yield stress of the material falls precipitously near the melting point. This modifies the stress around the weld and pushes the region of maximum compression into the heat affected zone (HAZ) adjacent to the weld pool itself. After solidification, the constrained thermal contraction of the weld bead generates large tensile stresses in the fusion zone. Of course, these tensile stresses in the weld and heat affected zone must be balanced by compression elsewhere in the weldment and therefore compressive stresses are found away from the heat affected zone. 
Maps of the hoop and axial stress determined from the lattice parameters obtained through Rietveld refinement of the data from ISIS are shown in Figure 7. The stresses are presented as filled and open circles showing tensile and compressive stresses respectively, with radii proportional to the magnitude of the stress. Trends may be observed in the spatial distribution of stresses around the weld that are consistent with those expected, as shown in the region identified by the grey dashed lines in Figure 6. The expected region of compression ahead of the weld is observed in both the longitudinal (hoop) and transverse (axial) directions and extends significantly ahead of the region heated by the weld torch, because of elastic accommodation around the heated region. This region of compressive stresses also extends some distance downstream of the weld pool at greater distances from the weld center line. In the far field behind the weld in the HAZ, tensile stresses are observed in the longitudinal direction and only small transverse stresses. In the heat affected zone 18 and $24 \mathrm{~mm}$ away from the center line a region of longitudinal compression extends behind the weld pool, as expected and shown in Figure 6.

The residual stress profile from such a weld might be expected to extend up to $\sim 70 \mathrm{~mm}$ away from the weld; the data has not been obtained to perform a stress balance between the compressive far-field and the tensile weldment regions. In the transverse and longitudinal directions compressive stresses were observed at the furthest measurement locations, $24 \mathrm{~mm}$ from the weld line. These were in excess of $300 \mathrm{MPa}$ for the transverse compressive stress and $\sim 220 \mathrm{MPa}$ for the longitudinal compressive stress.

[Fig. 8 about here.]

The data obtained from Chalk River using the $\{211\}$ peak could not be analysed successfully to obtain recognizable welding stress profiles. This is most probably due to the additional measurement direction required, three compared to the two required at ISIS, where the radial measurement is repeated to give a consistency check. The more independent measurements required, the more onerous the positioning demands, especially in the present case where the tube can distort during welding. The possibility that intergranular strains during the $\alpha \rightarrow \gamma$ and $\gamma \rightarrow \alpha$ transformations were responsible for the anomalous behaviour was examined by referring to the $\{211\}$ single peaks obtained at ISIS; this attempt failed to reconcile the two data sets. As a result of these considerations, the Chalk River stress measurements are not presented here.

The evolution of longitudinal stress obtained from the ISIS data along each track parallel to the weld is shown in more detail in Figure 8. Nearest the weld, $5 \mathrm{~mm}$ from the weld center line, the stress is slightly compressive $20 \mathrm{~mm}$ ahead of the torch and becomes more compressive closer to the weld pool, reaching $\sim 280 \mathrm{MPa}$ $10 \mathrm{~mm}$ ahead of the weld. As the weld pool is approached further the longitudinal stress remains compressive but decreases in magnitude as the local temperature is higher and the stress that the material can support is lower. No data was acquired 
from within the weld pool. $15 \mathrm{~mm}$ behind the torch large tensile stresses are seen with a peak stress of $\sim 530 \mathrm{MPa}$ being measured. Between 30 and $45 \mathrm{~mm}$ behind the torch the longitudinal stress decreases gradually to $\sim 200 \mathrm{MPa} .12 \mathrm{~mm}$ from the weld center line, the stress evolution simply shows a gradual rise from compression ahead of the weld to tension behind the weld. At $18 \mathrm{~mm}$ from the weld center line the longitudinal stresses are slightly in excess of $100 \mathrm{MPa}$ between 10 and $15 \mathrm{~mm}$ ahead of the weld. In the region between $5 \mathrm{~mm}$ ahead of the weld and $15 \mathrm{~mm}$ behind the weld compressive stresses $-70 \mathrm{MPa}$ to $-130 \mathrm{MPa}$ are seen, indicating that a region of compression extends behind the weld, as anticipated and illustrated in Figure 6. At larger distances behind the torch, near zero stresses are typically seen, suggesting that this distance from the weld center line will be close to the transition from tensile to compressive residual stress on completion of welding. The stresses obtained from the data acquired $24 \mathrm{~mm}$ from the weld center line show considerable point to point scatter but do indicate that compressive stresses are seen at this distance from the weld center line, with stresses of the order of $-200 \mathrm{MPa}$ both ahead and behind the weld torch and smaller magnitude compressive stresses in the region between $5 \mathrm{~mm}$ ahead and $5 \mathrm{~mm}$ behind the weld.

An indication of the uncertainty associated with the stress measurements is given for one of the data points. This uncertainty was derived from the accuracy with which all of the lattice parameters associated with each measurement location could be determined. In general, the level of accuracy of all of the data points are comparable to the one shown. The exception to this being those points in which both ferrite and austenite were observed and the volume fraction of ferrite was low.

In this study, the lack of reliable temperature data from within the neutron-irradiated gauge volume has limited the accuracy of the results obtained such that the stresses could only be measured in the ferrite phase with the assumption that the elastic constants were independent of temperature. It is recommended that in future a non-contact temperature method be used, measuring the same point as the incident beam. This would enable appropriate elastic moduli to be used for each data point and may allow determination of the hydrostatic strains with use of appropriate values of the coefficient of thermal expansion. In addition, it would be more desirable to use a finer grid of measurement positions than that used here. This would require significantly faster data acquisition times. Finally, the accuracy of the technique is limited by the requirement that the axial and hoop strains are measured from different welds. This introduces an uncertainty in the measurement positions, which is of greatest concern for those measurements conducted in regions with high temperature and stress gradients, such as those near the weld pool. This could be mitigated by measuring the two components together, which would require the diffraction angles employed to be small to avoid the unacceptably long count times necessary to obtain adequate coating statistics with the large path lengths that would be required. This could most readily be achieved with the use of a high energy synchrotron source. 


\section{Conclusions}

The phase and stress evolution around a ferritic steel GTAW weld have been characterised using in situ neutron diffraction. The following conclusions can be drawn from this work

- A novel method has been developed to isolate the deviatoric or plane stress state in the presence of isotropic contributions to the lattice parameter such as thermal expansion and solute content. The method can be applied using constant wavelength or time-of-flight neutron diffraction.

- The stress state was found to evolve in the anticipated manner, with compressive stresses ahead of the weld torch and tensile stresses behind the weld torch in the weld and heat affected zone, and compression in the far field behind the weld.

- Importantly, the region of compression in the heat-affected zone adjacent to and just behind the welding torch expected from weld models is observed.

- The evolution of phase fraction around the weld can be observed using the technique.

The technique can also be applied to examine materials and processes where the stress state is modified to minimise cracking and/or to produce compressive stresses in the weldment itself, such as in steels which exhibit transformation-induced stress relaxation or in low-stress low-distortion welding; this should provide a fruitful avenue for future investigation.

\section{Acknowledgements}

This work was largely conducted when DD was an NSERC visiting fellow at Chalk River. Contributions to the experiment design from John Fox, Kelly Conlon and John Root at NRC Chalk River are acknowledged. Al Lockley at AECL Chalk River prepared the micrographs in Figure 2. Edward C Oliver provided invaluable assistance in performing the experiments at ISIS.

\section{References}

[1] S. S. Babu, J. W. Elmer, J. M. Vitek, and S. A. David, Time-resolved X-ray diffraction investigation of primary weld solidification in $\mathrm{Fe}-\mathrm{C}-\mathrm{Al}-\mathrm{Mn}$ steel welds, Acta Materialia 50 (2002), no. 19, 4763-4781.

[2] M. R. Daymond, M. A. M. Bourke, R. B. VonDreele, B. Clausen, and $\mathrm{T}$. Lorentzen, Use of rietveld refinement for elastic macrostrain determination and for evaluation of plastic strain history from diffraction spectra, Journal of Applied Physics 82 (1997), no. 4, 1554-1562. 
[3] A. De and T. DebRoy, A perspective on residual stresses in welding, Science and Technology of Welding and Joining 16 (2011), no. 3, 204-208, cited By (since 1996)7.

[4] D. Deng and H. Murakawa, Influence of transformation induced plasticity on simulated results of welding residual stress in low temperature transformation steel, Computational Materials Science 78 (2013), 55-62.

[5] Dean Deng, Hidekazu Murakawa, and Wei Liang, Numerical and experimental investigations on welding residual stress in multi-pass butt-welded austenitic stainless steel pipe, Computational Materials Science 42 (2008), no. 2, $234-244$.

[6] D. Dye, O. Hunziker, and R. C. Reed, Numerical analysis of the weldability of superalloys, Acta Materialia 49 (2001), 683-697.

[7] D. Dye, O. Hunziker, S. M. Roberts, and R. C. Reed, Modeling of the mechanical effects induced by the tungsten inert-gas welding of the IN718 superalloy, Metallurgical and Materials Transactions A 32A (2001), 1713-1725.

[8] D. Dye, S. M. Roberts, A. M. Korsunsky, K. E. James, B. Benn, and R. C. Reed, Application of low stress low distortion welding to the gas tungsten arc welding of wrought nickel-base alloy C263, Mathematical Modelling of Weld Phenomena 6 (H. Cerjak, ed.), 6th International Seminar on Numerical Analysis of Weldability, Schloss Seggau, Graz, AUSTRIA, OCT, 2001, 2002, pp. 751-765.

[9] J. W. Elmer and T. A. Palmer, In-situ phase mapping and direct observations of phase transformations during arc welding of 1045 steel, Metallurgical and Materials Transactions A 37A (2006), no. 7, 2171-2182.

[10] J. W. Elmer, T. A. Palmer, S. S. Babu, W. Zhang, and T. DebRoy, Direct observations of austenite, bainite, and martensite formation during arc welding of 1045 steel using time-resolved X-ray diffraction, Welding Journal 83 (2004), no. $9,244 \mathrm{~S}-253 \mathrm{~S}$.

[11] J. W. Elmer, T. A. Palmer, and Joe Wong, In situ observations of phase transitions in ti-6al-4v alloy welds using spatially resolved $x$-ray diffraction, Journal of Applied Physics 93 (2003), no. 4, 1941-1947.

[12] J.W. Elmer, T.A. Palmer, and E.D. Specht, In situ observations of sigma phase dissolution in 2205 duplex stainless steel using synchrotron x-ray diffraction, Materials Science and Engineering: A 459 (2007), no. 12, 151 - 155.

[13] Z. Feng, X.-L. Wang, S. A. David, and P. S. Sklad, Modelling of residual stresses and property distributions in friction stir welds of aluminium alloy 6061-T6, Science and Technology of Welding and Joining 12 (2007), no. 4, 348-356.

[14] J. Goldak, V. Breiguine, and N. Dai, Computational weld mechanics: A progress report on ten grand challenges, Trends in Welding Research $(\mathrm{H}$. B. Smartt, J. A. Johnson, and David S. A., eds.), 4th International Conference on Trends in Welding Research, GATLINBURG, TN, JUN 05-08, 1995, 1996, pp. 5-11.

[15] X. He, J. W. Elmer, and T. DebRoy, Heat transfer and fluid flow in laser microwelding, Journal of Applied Physics 97 (2005), no. 084909. 
[16] A. C. Larson and R. B. Von Dreele, General structure analysis system (GSAS), Tech. Report LAUR 86-748, Los Alamos National Laboratory, 1994.

[17] S. Mishra and T. DebRoy, A heat-transfer and fluid-flow-based model to obtain a specific weld geometry using various combinations of welding variables, Journal of Applied Physics 98 (2005), no. 04902.

[18] M. Onink, C. M. Brakman, F. D. Tichelaar, E. J. Mittemeijer, S. Vanderzwaags, J. H. Root, and N. B. Konyer, The lattice-parameters of austenite and ferrite in $\mathrm{Fe}-\mathrm{C}$ alloys as a function of concentration and temperature, Scripta Metallurgica et Materialia 29 (1993), no. 8, 1011-1016.

[19] R. V. Preston, H. R. Shercliff, P. J. Withers, and S. Smith, Physically-based constitutive modelling of residual stress development in welding of aluminium alloy 2024, Acta Materialia 52 (2004), no. 17, 4973-4983.

[20] A.P Reynolds, Wei Tang, T Gnaupel-Herold, and H Prask, Structure, properties, and residual stress of 3041 stainless steel friction stir welds, Scripta Materialia 48 (2003), no. 9, 1289 - 1294.

[21] H. J. Stone, S. M. Roberts, and R. C. Reed, A process model for the distortion induced by the electron-beam welding of a nickel-base superalloys, Metallurgical and Materials Transactions A 31A (2000), no. 9, 2261-2273.

[22] H. J. Stone, P. J. Withers, T. M. Holden, and R. C. Reed, Comparison of three different techniques for measuring the residual stresses in an electron beam-welded plate of waspaloy, Metallurgical and Materials Transactions A 30 (1999), no. 7, 1797-1808.

[23] W. Woo, Z. Feng, X.-L. Wang, D.W. Brown, B. Clausen, K. An, H. Choo, C.R. Hubbard, and S.A. David, In situ neutron diffraction measurements of temperature and stresses during friction stir welding of 6061-t6 aluminium alloy, Science and Technology of Welding and Joining 12 (2007), no. 4, 298303.

[24] W. Woo, Z. Feng, X.-L. Wang, and S.A. David, Neutron diffraction measurements of residual stresses in friction stir welding: A review, Science and Technology of Welding and Joining 16 (2011), no. 1, 23-32.

[25] W Zhang, J.W Elmer, and T DebRoy, Modeling and real time mapping of phases during $\{G T A\}$ welding of 1005 steel, Materials Science and Engineering: A 333 (2002), no. 12, $320-335$. 


\section{List of Figures}

1 Schematic illustration of the two setups used at ISIS for measurement of (a) the radial and hoop and (b) the radial and axial lattice parameters; (c) photograph of the axial setups used at ISIS and (d) Chalk River during welding.

2 (a) macrograph of the weld cross-section (with the tube seam below), micrographs of the (b) parent metal, (c) heat affected zone and (d) fusion zone microstructures.

3 Diffraction data associated with the measurements made of the hoop strain component. The data shown is from the measurements made from $10 \mathrm{~mm}$ ahead of the weld to $25 \mathrm{~mm}$ behind the weld along a track at $5 \mathrm{~mm}$ from the weld path. The peak positions of the $\alpha$ - ferrite and $\gamma$ - austenite are identified.

$4 \quad$ Map of the austenite phase fraction around the weld, obtained from Rietveld refinement of the diffraction data collected. Note that additional data points are included in the vicinity of the weld from which no strain data were acquired. Material in the two-phase region is denoted by open circles.

5 Map of the measured $a_{0}$ lattice parameter of ferrite, relative to the lattice parameter at room temperature $a_{0}(R T)$, $\left(a_{0}-a_{0}(R T)\right) / a_{0}(R T), \times 10^{-6}$, obtained from (a) the $\{211\}$ ferrite peak (Chalk River) and (b) Rietveld refinement of the diffraction data (ISIS).

6 Expected variation of temperature and longitudinal stress around a weld in a single phase material. The dashed grey box provides an indication of the equivalent region of interest from which the in situ measurements reported in Figures 5 and 7 were made.

7 Maps of the hoop (top) and axial (bottom) stresses in the ferrite, determined from the measured data around the weld.

8 Plots of hoop stress in the ferrite along the welding direction at distances between 5 and $24 \mathrm{~mm}$ from the weld path. 


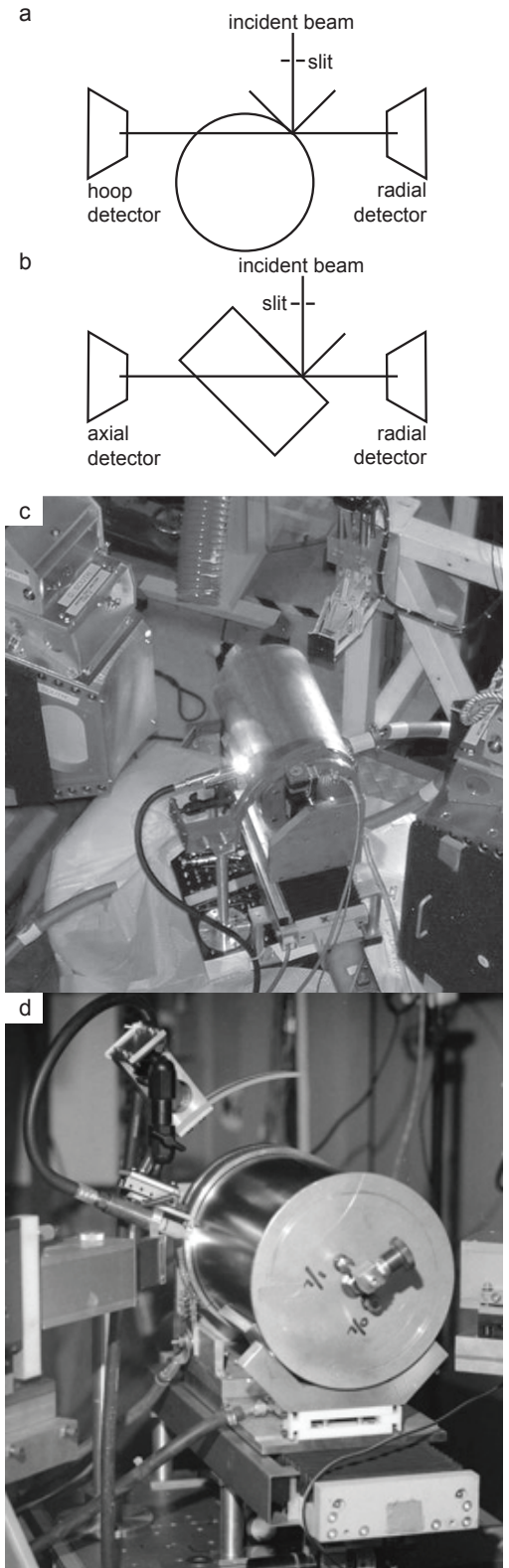

Fig. 1. Schematic illustration of the two setups used at ISIS for measurement of (a) the radial and hoop and (b) the radial and axial lattice parameters; (c) photograph of the axial setups used at ISIS and (d) Chalk River during welding. 


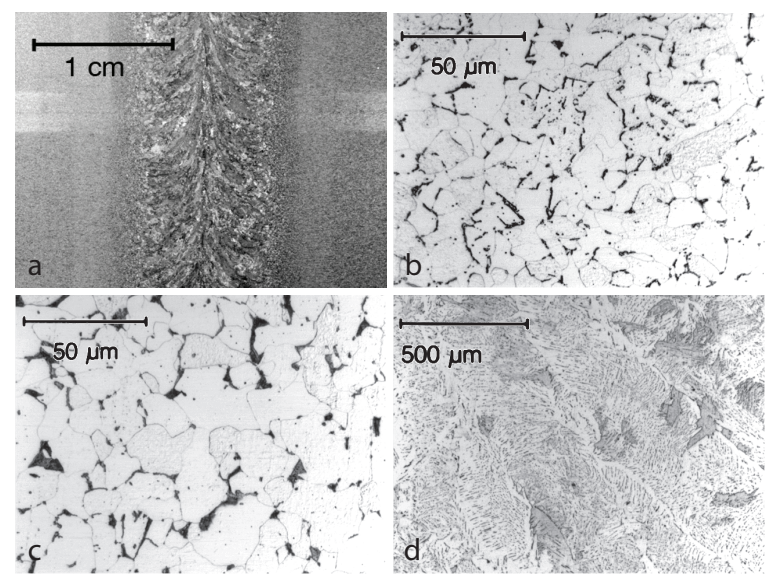

Fig. 2. (a) macrograph of the weld cross-section (with the tube seam below), micrographs of the (b) parent metal, (c) heat affected zone and (d) fusion zone microstructures. 


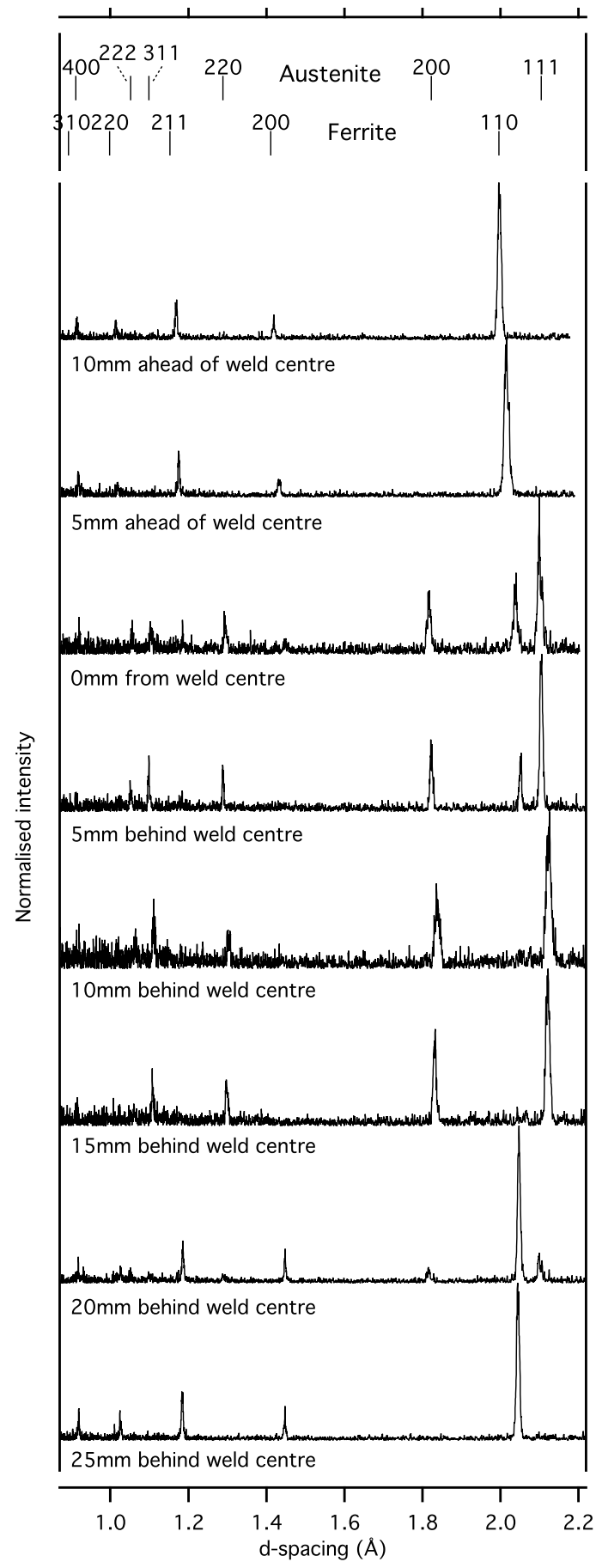

Fig. 3. Diffraction data associated with the measurements made of the hoop strain component. The data shown is from the measurements made from $10 \mathrm{~mm}$ ahead of the weld to $25 \mathrm{~mm}$ behind the weld along a track at $5 \mathrm{~mm}$ from the weld path. The peak positions of the $\alpha$ - ferrite and $\gamma$ - austenite are identified. 


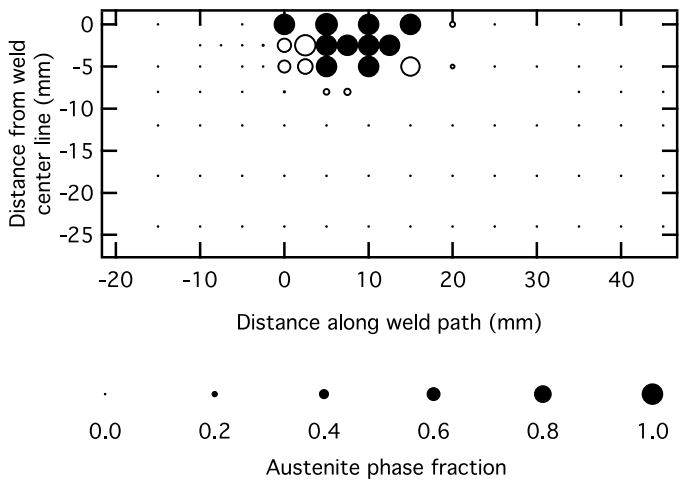

Fig. 4. Map of the austenite phase fraction around the weld, obtained from Rietveld refinement of the diffraction data collected. Note that additional data points are included in the vicinity of the weld from which no strain data were acquired. Material in the two-phase region is denoted by open circles. 

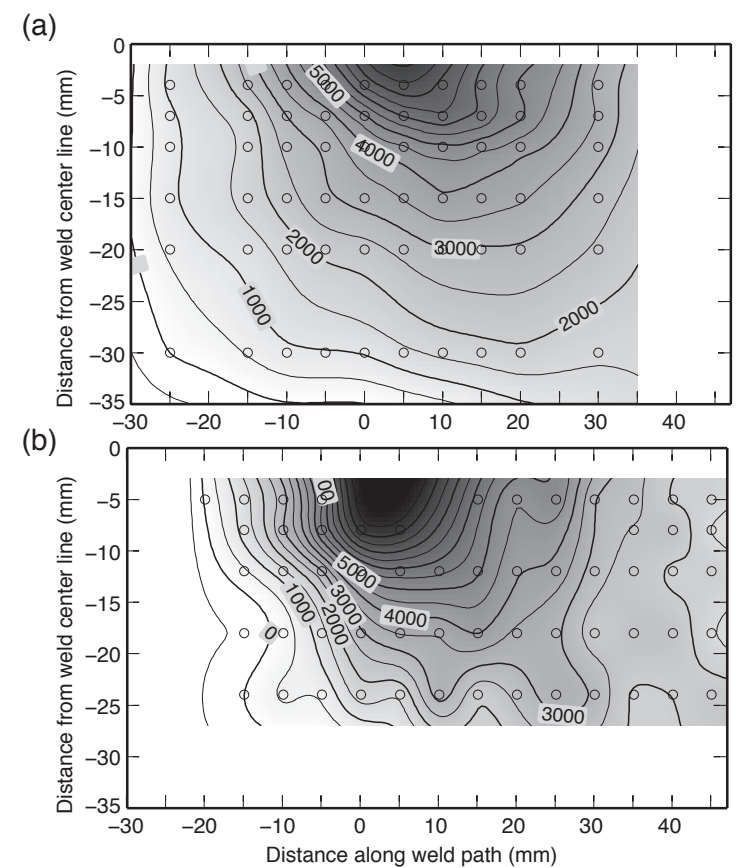

Fig. 5. Map of the measured $a_{0}$ lattice parameter of ferrite, relative to the lattice parameter at room temperature $a_{0}(R T),\left(a_{0}-a_{0}(R T)\right) / a_{0}(R T), \times 10^{-6}$, obtained from (a) the $\{211\}$ ferrite peak (Chalk River) and (b) Rietveld refinement of the diffraction data (ISIS). 

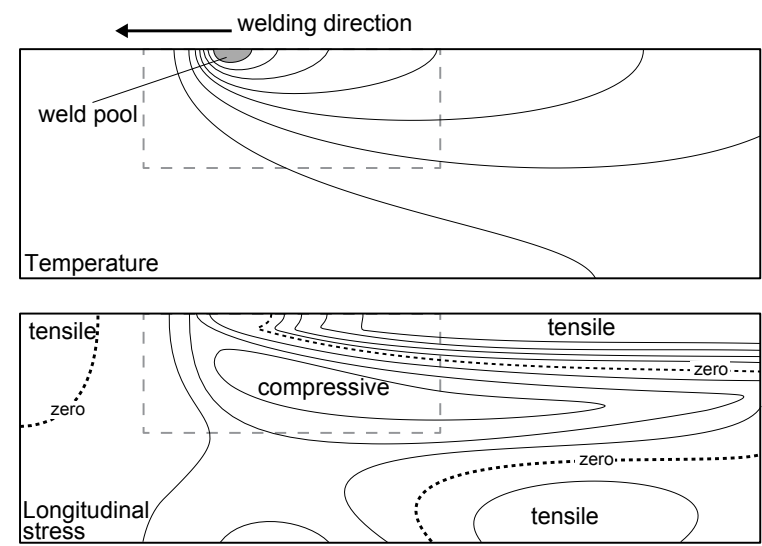

Fig. 6. Expected variation of temperature and longitudinal stress around a weld in a single phase material. The dashed grey box provides an indication of the equivalent region of interest from which the in situ measurements reported in Figures 5 and 7 were made. 


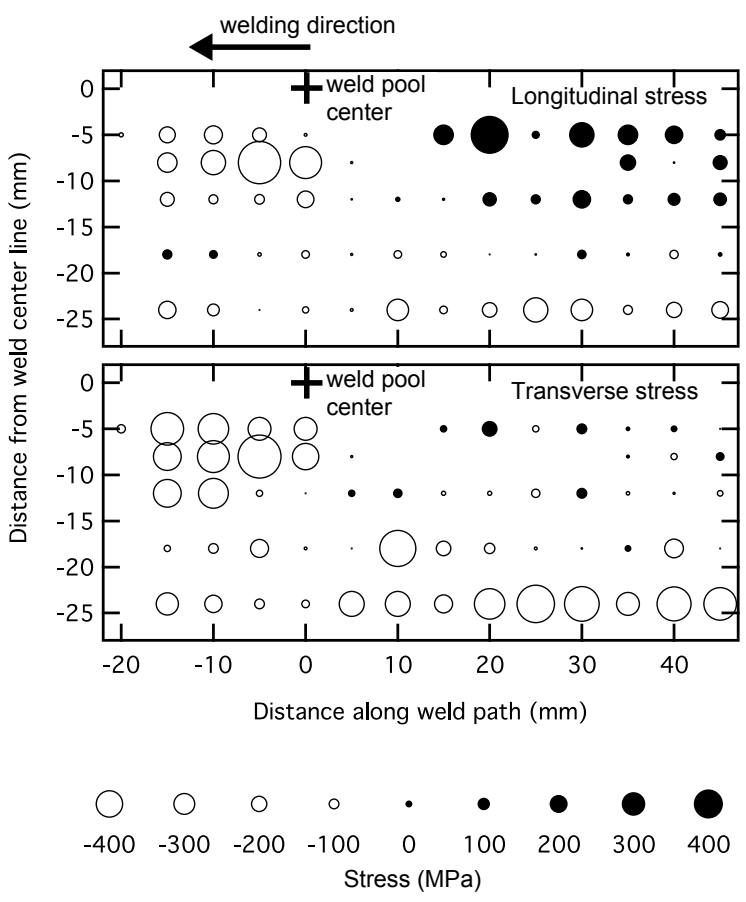

Fig. 7. Maps of the hoop (top) and axial (bottom) stresses in the ferrite, determined from the measured data around the weld. 


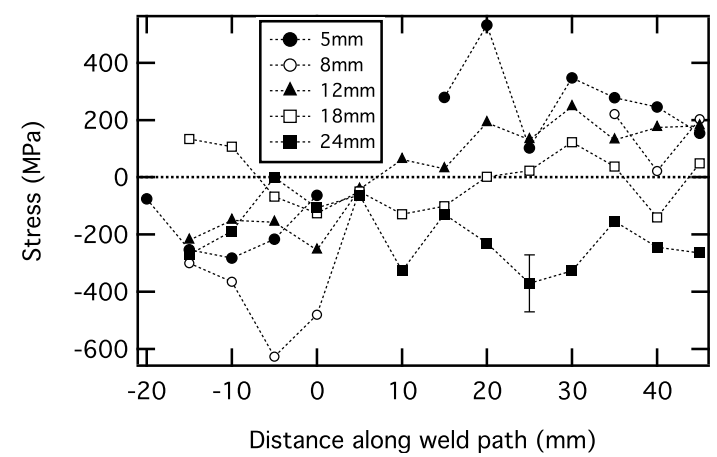

Fig. 8. Plots of hoop stress in the ferrite along the welding direction at distances between 5 and $24 \mathrm{~mm}$ from the weld path. 